\title{
Ethical and Compliance-Competence Evaluation: A Key Element of Sound Corporate Governance.
}

\author{
Abstract \\ Motivated by the ongoing post-Enron refocusing on corporate governance and the \\ shift by the Financial Services Authority (FSA) in the UK to promoting compliance- \\ competence within the financial services sector, this paper demonstrates how template \\ analysis can be used as a tool for evaluating compliance-competence. Focusing on \\ the ethical dimension of compliance-competence, we illustrate how this can be \\ subjectively appraised. We propose that this evaluation technique could be utilised as \\ a starting point in informing senior management of corporate governance issues and \\ be used to monitor and demonstrate key compliance and ethical aspects of an \\ institution to external stakeholders and regulators.
}

Keywords: Ethics, compliance-competence, template analysis, corporate governance

\section{Introduction}

An increasingly important aspect of the everyday life of any corporate business and especially that of UK financial institutions is, to be able to demonstrate to regulators and other external stakeholders, compliance with and competence in regulatory requirements. The UK financial services regulator ${ }^{i}$ has, since the Financial Services Act 1986 and its replacement the Financial Services and Markets Act 2000, established a regulatory framework and set compliance standards, which are an example to all. Lessons from how UK financial services have moved from a system of self-regulation to statutory control and from detailed rulebooks to the more recent high-principled regulatory approach (Tiner, 2005), provide an example to all wishing 
to develop a transparent and accountable regulatory system. To this end the UK financial services evolving regulatory system has much to offer, not only to other financial services systems but also to the corporate world as a whole. Closely linked to this is how exactly can an institution analyse, monitor and present its behaviour to the market? Mallin et al. (2005) stress the importance of being able to monitor an institution's corporate governance performance when endeavouring to define the term ‘corporate governance’. They highlight the need for institutional investors, under the provisions of the Combined Code (2003), to take 'all factors into account when assessing a company's corporate governance'. The extent to which financial services institutions are compliant-competent and adopt an ethical approach to their business is a strong indicator of senior management's commitment to compliance-competence and corporate governance in general. Research by Jackman ${ }^{\mathrm{ii}}$ (2001a) in the context of compliance-competence proposes a model for the development of institutional values and culture. It enables the Financial Services Authority (FSA) to consider the culture of the institution and to ascertain whether or not it is meeting the overall aims of the Financial Services and Markets Act 2000. The benefit for those regulated can be said to be the possibility of a lighter regulatory touch by the regulator. The Jackman model, set in the context of financial services regulation, can be used as a starting point for addressing issues of compliance-competence. The Jackman model is important because it was the first and only model offered to date by the FSA that recognises the need and benefit of developing a firm's values and culture, so that the regulator may adopt a lighter regulatory touch. Wood (2002) offers a broader and more elaborate ethical model from an Australian experience, which focuses on the development of an appropriate ethical culture arising from the firm's internal commitment to change supported by a wide range of stakeholders. An appropriate 
ethical culture is an intangible set of values, beliefs and rules of behaviour, which are part of the 'social glue' (Baker, 1980) of the organisation. Unlike rules that tell you how to act, ethics tell you how to think before acting. The appropriate ethical culture should result in the organisation and its employees demonstrating professional standards of integrity, honesty, fairness and responsibility.

A core objective of our paper is to show how the Jackman model might be operationalised and how it might be improved upon by utilising template analysis. A financial institution is compliance-competent when it complies with all applicable laws, regulations, codes of conduct and standards of good practice and has an open and positive relationship with its regulator/s. To this end an ethical approach to an institution's business that is fully internalised may be said to meet many, if not all, of the above requirements. To develop a tool for evaluating the extent to which a financial institution can be classified as compliance-competent, ${ }^{\text {iii }}$ we draw on the use of template analysis and demonstrate how it might be used in practice. Template analysis is a widely adopted approach in qualitative research and is often referred to as ‘codebook analysis’ or ‘thematic coding’ by some academics (King, 1998, pp. 118134). It is a highly flexible method of interpreting interview material, in order to develop a hierarchical structure of common themes, patterns, or categories of meaning. The template of analysis developed from a case study within Skandia Life (Skandia), a UK based life assurance company, provides a tool to evaluate and inform on ethical progression, which is a major element of an institution's compliancecompetence. 
This paper contributes to the literature in three ways. Firstly, it provides an analysis of how compliance-competence can be evaluated for financial institutions by focusing on the ethical dimension. Secondly, we modify and advance the model advocated by Jackman. Thirdly, we provide a valuable practical insight into ethics within a commercial setting. Finally, we suggest that template analysis and an ethical approach to financial services can be adopted by the wider business community and set within a corporate governance framework.

The remainder of this paper is organised as follows. Section one draws upon key literature that establishes the importance of ethics in the context of compliancecompetence. Section two presents the case study and explains the development of one aspect of the template of evaluation, which highlights the ethical dimension of compliance-competence. Section three presents the core compliance and ethical conclusions for Skandia, before concluding with a summary of the value of the template as a tool of analysis which can be adopted as a means of demonstrating to external stakeholders an institution’s level of compliance-competence.

\section{Compliance-competence and ethics}

The difficulty in defining the term 'compliance' with any real precision is noted by Parker (2002, p.22). Parker, in seeking to define what is meant by a 'corporate compliance program', states that it consists of 'a broad continuum of relevant corporate practices ranging on the one hand from formal legalistic compliance management systems to vague ethics or codes of conduct and from legally-orientated to quality-orientated management systems on the other'. Further she advocates that: 
Legalistic or rule compliance on its own is an inadequate criterion for assessing compliance systems because it connotes a reactive conception of the corporation as a recipient of rules, rather than an actively responsible citizen. The term 'compliance' is too passive to indicate that it is engaged with its legal, social, environmental and ethical responsibilities. Indeed, some leading compliance consultants prefer the term 'integrity programme', because 'compliance' connotes a simplistic obedience to rules rather than engagement with ethical and social responsibilities (p.27).

This latter and more enlightening interpretation of compliance is more in keeping with the Jackman model of compliance-competence, which seeks to develop the correct corporate values and culture based upon an appropriate ethical approach. Newton (1998) in his work on compliance offers us a practical approach to establishing ethical behaviour and systems in financial services. This is complemented by Moon and Bonny (2001), a collection of papers written by those who specialise in or are closely involved in the field of business ethics. The papers highlight the importance of ethical issues and how these might be practically addressed. It is essential for the regulated and the regulator to have a clear understanding of compliance-competence. As previously stated an institution may be said to be compliance-competent when it complies with all applicable laws, regulations, codes of conduct and standards of good practice and has an open and positive relationship with its regulator/s. However, compliance-competence needs to be explained in simple verifiable terms of actions and behaviours. The regulator needs to see evidence of such behaviour and therefore needs to work closely with those it regulates to provide a common understanding and approach.

The Jackman model (2001a) identifies within a single firm a spectrum of values and culture development. This spectrum ranges from a minimum compliance approach (level 1), to a mature compliance relationship between the regulator and the regulated 
(level 4). The institution will evolve from a minimum standard approach evidenced by an 'unthinking and mechanical approach to compliance' to an aspirational culture (level 2) which has 'sound intentions and aims to do more than the minimum, yet relies upon guidance from the regulator' and has a 'bureaucratic approach' to compliance. The ethical culture stage (level 3) includes, among other things, a proactive ethical approach to its business, with 'effective systems and controls', risk focused and very much 'self policing'. The final mature relationship stage (level 4) is an institution which aims to go 'beyond the rules', with a proactive approach to compliance evidenced by ‘individual responsibility and ownership’ of compliance issues, and 'awareness and discussion of ethical issues at senior level' complemented with 'an open relationship with the FSA'. Jackman has suggested that the FSA will adopt a lighter regulatory touch, as the institution moves up the spectrum of compliance-competence, from level 1 to 4 on the Jackman model.

Wood (2002) offers a more elaborate partnership model based in ethics. Wood's model is built upon two elements, 'commitment and partnerships':

This ethical model requires a commitment to partnerships with all stakeholders both internal and external in an attempt to enhance the ethical business practices that are contemplated and pursued within corporate Australia (p. 61).

The model (p.64) is represented in a figure, which consists of four layers. The first and inner layer at the very core of the model is the 'commitment to an ethical culture', which he sees as the heart of the institution and needs to be embodied in corporate practice. He expands on this in the second layer as the 'company needs to ensure a commitment to their staff and shareholders', while recognising that the company has a wider responsibility to a 'range of groups outside the institution upon whom they impact' (p.63). This layer again recognises the important role of senior management 
to set the 'ethical tone' and to ensure the establishment of an ethical culture. The next and third layer of commitment he identifies as 'ethical institutional artefacts' include such things as: staff selection processes, codes of ethics, ethics training, ethics committees, whistle-blowing and even an ethics ombudsman. He sees these as practical measures that will 'assist staff to understand and comply with the ethical ethos of the institution' (p.65). The final and outer layer is identified as the 'commitment to ethics in the market place'. This includes the wider stakeholders such as customers, suppliers, government, external bodies and pressure groups.

Thus, practitioners and authors such as Jackman (2001a and b, 2004) and Wood (2002) highlight the need for an ethical framework for financial services. While Jackman focuses upon creating a practical internal compliance-competence model for the UK financial services sector based upon the development of appropriate corporate values and culture within the organization (2001a, p.213), of which ethics is a key component part, Wood (2002, p.64) an academic and practitioner, provides a much broader ethical model based upon 'commitment' and 'partnership', with a wider range of 'stakeholders' external to the organization itself.

Jackman (2001a, p.212) highlights the benefit of an ethical approach as being less regulation. He argues that the development of 'value systems that go beyond compliance standards and build up a safety cushion against behaviour slipping to, and below, an acceptable level' is a legitimate focus for the FSA. He identifies the core requirement of value-led regulation as being the 'building of integrity, honesty, fairness and responsibility.' This value-led approach, he believes, is about changing the attitudes and approaches of individuals and cultures. Such a change 'cannot be 
forced; it can only come from within' and the role of the FSA in its regulatory approach 'must help firms to go beyond mere compliance to a more active engagement with the values underlying the legislation.’ A value-led approach is very much in keeping with the Higg's Report (2003), which adopted an holistic approach to corporate governance and emphasised the importance of cultural change. Although the Jackman model is a good starting point it benefits from review and further development. The model provides a workable framework but may be said to suffer somewhat when abstract concepts of ethics and integrity are adopted and perhaps is rather internally focussed. The concept of compliance-competence and the need to modify corporate culture so that it is ethical and more of a partnership between the FSA and those it regulates, has been highlighted by Edwards (2003a, 2003b), (Edwards and Wolfe (2004, 2005)). This somewhat broader partnership approach includes three main elements, each of equal importance and intrinsically linked. They include good compliance practice, good ethical practice and a positive regulatory relationship.

The importance and currency of an ethical approach is evidenced by the most recent FSA initiatives in conjunction with the recently formed Financial Services Skills Council. The FSA launched its 'Ethical Framework for Financial Services' discussion document in October 2002, which has been complemented by the 'Integrity in Practice’ paper (Skills Council for Financial Services, 2003). The authors Jamison and Steare seek to identify what is meant by the term 'business ethics' and begin with an historical academic discourse of ethical systems before seeking to identify the key elements of what they suggest are needed for an ethical foundation for financial services (Section 3). They state in the final section that the financial 
services industry may develop its sense of integrity 'step-by-step, through moral discussion'. They conclude that 'each member firm has both the right and duty to contribute to an on-going industry-wide debate' (p.8). Of course this reference to an integrity-based approach is not new.

Paine (1994) favours an integrity-based approach to ethics management that should combine 'a concern for the law with an emphasis on managerial responsibility for ethical behavior' (p.111). Paine states that 'organizational ethics helps define what a company is and what it stands for' and that the integrity strategy necessary to achieve this is 'broader, deeper, and more demanding than a legal compliance initiative' (p.111). Such an ethical approach fits well with corporate governance. While it can be said that corporate governance covers a broad spectrum of concepts and phenomena an ethical approach lends itself as a means of improving corporate governance. The Organisation for Economic Cooperation and Development (OECD, 1999) refers to corporate governance as a system by which business corporations are directed and controlled and acknowledges that the governance structure needs to specify the' distribution of rights and responsibilities among different participants in the corporation' It highlights the importance of spelling out the rules and procedures for decision making. In light of the financial scandals and malpractices that have taken place it is advocated that an ethical perspective to corporate governance may offer a way forward. Arjoon (2005) argues that legal compliance mechanisms are in themselves insufficient to deal with fraudulent practices and therefore ethical compliance mechanisms which inspire ethical behaviour have a part to play. Arjoon believes in the development of the right ethical culture with a greater emphasis on integrity and trust. In conclusion he states that 'effective corporate governance based 
on core values of integrity and trust' will enhance the organisation's reputation and improve its position in the market place. This in turn should increase customer loyalty and heighten employee commitment.

Thus current practitioner and academic interest in the issue of ethics and compliancecompetence within the financial services sector has been the catalyst for this research and the resulting case study. To this end the Jackman model may be adopted as a starting point as it recognises a much broader and ethical dimension to compliancecompetence. However to enhance its value in an operational sense, an institution needs to elaborate and highlight the key elements associated with its compliancecompetence. This may be achieved by the use of template analysis (King, 1998). This is an evaluation tool that provides a framework for highlighting the key issues most relevant to the institution and demonstrates to external stakeholders not only the structured process of review undertaken but also the outcomes in a structured and hierarchical template of analysis.

\section{Skandia and template analysis}

The case study was carried out at Skandia Life (Skandia). Skandia, founded in 1979, is the Southampton-based arm of the Swedish Insurance Company Limited, which was founded in 1855 and has been quoted on the Stockholm stock exchange since 1863. Skandia has rapidly become a major force in the unit-linked UK life and pensions industry and is ranked among the UK’s top ten life financial services groups. Skandia employs approximately 2,500 people at its Southampton headquarters and has approximately $£ 12$ billion of funds under management. Skandia bases its business strategy on the belief in the value of independent recommendation and accordingly 
offers its range of savings, investment, pension and protection products through independent financial advisers (IFAs).

The research adopted an inductive approach, set within a single case study. It identifies key issues, constructs concepts/theories and leads to generalisations that may be applied in other institutions. The term case study is used in accordance with the criteria established by Yin (2003). The case study is in parts explanatory, descriptive and illustrative but such distinctions are not always 'necessarily clear-cut' Scapens (1990, p265). The opportunity to use Skandia arose by ‘chance’ (Otley and Berry, 1994) due to a long standing academic relationship with the researcher. The primary case study data was gathered in a series of ten in-depth interviews with senior and middle management at Skandia. The interviewees were selected on the basis of hierarchical structure and functional areas identified by the researcher's own experience and in consultation with key Skandia personnel. The interviews took the form of a semi-structured interview based on a detailed questionnaire ${ }^{\text {iv }}$ consisting mainly of open-ended questions. The aim of the questionnaire was to develop a template of analysis that closely reflected the issues associated with a compliancecompetent institution as outlined in the Jackman model. All interviewees received an introductory letter that provided brief details of the researcher and the research aims. This was accompanied by three documents: the Jackman and Wood models and a copy of the FSA's ethical framework briefing sheet. The interviews took approximately one hour, were all audiotape recorded, transcribed and supported by interview notes. The interviews were supported by an extensive academic and industry literature review. 
In order to achieve an analytical review and analysis of the interview data, 'template analysis' was used (King, 1998). ${ }^{\mathrm{v}}$ This is a flexible and extremely useful and appropriate method to interpret and analyse text. It lends itself to the on-going research journey of discovery and provides the framework for the development of themes of understanding, which help with aspects of conceptualisation and potential generalisations. Template analysis was adopted with the initial focus arising from the key elements of compliance-competence highlighted by Jackman. The key elements were elaborated upon and enriched by the data arising from the interviews.

The researcher kept a questionnaire and template diary to systematically log changes and to assist with the evolution of the template, by confirming the themes and issues of compliance-competence and the hierarchical nature of analysis, thereby enabling the researcher to 'analyse texts at varying levels of specificity' (King, 1998, pp. 119120). King outlines a process of working systematically through the full set of transcripts in order to identify sections of the text which are relevant to the research aims and then marking them with one or more appropriate code(s) from the initial template. As King states, 'Put simply, a code is a label attached to a section of text to index it as relating to a theme or issue which the researcher has identified as important to his or her interpretation' (1998, p.119). This research utilised the terms of 'themes and issues' rather than 'codes' because it more accurately reflected the nature of the matters under consideration within the case study and provided a clearer distinction between the hierarchical levels identified. The interviews were the means for defining and refining the hierarchical levels of analysis and the themes and issue therein. It was the identification of these themes and issues, by the matching or mismatching of the text, which revealed the inadequacies of the template and 
provided the necessary insight which enabled the researcher to amend and develop the template until satisfactory conclusion. The four themes identified from the template analysis at the first and broadest level of analysis (level one) were regulatory, compliance, ethics and partnership. $^{\mathrm{vi}}$ The ethical theme is the focus of this paper, which is linked to the compliance theme by the statements made by the interviewees. Further and more detailed levels of analysis underpin these themes and are referred to as levels two, three and four. Levels two, three and four identify the underlying issues arising out of compliance-competence and the relationship between the regulator and the regulated.

The template underwent an eight-stage development process. In version one the template was identical to the questionnaire and consisted of four sections based upon the Jackman model. Subsequent and more detailed and sophisticated versions (1-8) were developed following the interviews and analysis of responses. It was not necessary to regimentally code all the interview transcripts but rather to look for recurring themes and issues, confirmation of statements made by previous interviewees and amendment or removal of matters not repeated in the interview process. This in turn resulted in amendments to the template as well as providing fresh insight, which generally informed the research process. The interview transcripts, which were on the whole fully transcribed, were rigorously scrutinised and used to produce a set of key summary points. These summary points were then cross-matched to the existing template to check on existing themes and issues for confirmation and comparison. This resulted in amendment or additions being made to the existing hierarchical levels of analysis. This supports King's observation that 'it is crucial to recognise that the development of the template is not a separate stage from 
its usage in analysis of texts' and that 'in qualitative template analysis, the initial template is applied to analyse the text through the process of coding, but it is itself revised in the light of ongoing analysis' (1998, pp.121-122). Figure 1 is the final version of the ethical part of the template of analysis. 
Figure 1: Extract from final template version 8. (Ethical Theme 3)

3 ETHICAL APPROACH

(LEVEL 1)

3.1 UNDERSTANDING/ACCEPTANCE

(LEVEL 2)

3.1.1 SKANDIA'S POSITION

(LEVEL 3)

3.1.2 INTERNAL/EXTERNAL

3.1.3 BUSINESS DRIVER

3.1.4 NEED TO IDENTIFY ETHICAL RISK AREAS

3.1.5 RECOGNITION OF ETHICAL SUB-CLIMATES

3.2 IMPLEMENTATION

3.2.1 SKANDIA'S ETHICAL GUIDELINES

3.2.1.1 NEED TO BE LOCALISED (LEVEL 4)

3.2.1.2 GREATER AWARENESS

3.2.1.3 BETTER COMMUNICATION

3.2.1.4 REWARD INCENTIVES

3.2.2 SKANDIA'S FUNDAMENTAL VALUES

3.2.2.1 VALUES COMMITTEE ROLE (ETHICS COMMITTEE)

3.2.2.2 NEED TO REPRESENT AS A SET OF BEHAVIOURS

3.2.3 LED BY SENIOR MANAGEMENT

3.2.3.1 SENIOR MANAGEMENT COMMITMENT

3.2.3.2 RISK SERVICES DRIVEN

3.2.4 WHISTLE-BLOWING

3.2.4.1 ESCALATION

3.2.4.2 SYSTEMS NEEDED

3.2.4.3 DIVISIONAL TENSIONS, WHERE IS RESPONSIBILITY

3.2.4.4 NEED SUPPORT WHEN THEY ACT

3.3 APPLICATION

3.3.1 STAFF OWNERSHIP

3.3.2 STAFF INDUCTION

3.3.3 STAFF APPRAISAL 
Level one is the first and highest level of analysis and consists of the main themes whereas level four is the most specific and detailed. In figure 1, the ethical approach, level one (3), breaks down into three level two points of analysis, namely: (3.1) understanding/acceptance, (3.2) implementation and (3.3) application. It also highlights a number of additional sub points of analysis, at level three and four, for example, Escalation (3.2.4.1, level four) refers to the way Skandia deals with the concept of whistle-blowing (3.2.4, level three), which in turn is considered as one of the ways it has implemented (3.2, level two) an ethical approach (3, level one).

The content of the template developed arises from academic and practitioner literature, based upon a constructivist view of research (Creswell (2003), Lincoln and Guba (2000), Newman and Schwandt, (2000)). It can also be said to have arisen and be akin to what has been described as 'skeletal theory’ (Laughlin (2004) p.268), as it provides a means to interrogate and analyse empirical data by providing a framework by which to review it, which in part, relies upon the detail itself to make the 'skeleton live'. As Laughlin points out such 'theories' are 'not pregivens' but need discovery and such discovery 'comes through extensive engagement with empirical situations, initially to formulate their nature and then subsequently to provide a framework of understanding further empirical situations which in turn, provides the base for developing their ongoing nature'. Therefore the template produced arises from the understanding gleaned from the initial interviews and the supporting literature, which in turn is improved upon and enhanced by additional data acquired from subsequent interviews and analysis. The template produced is therefore a starting point which can be utilised and adopted for future use, not only within the financial services sector but also in the wider field of corporate governance. 
In the UK we have no equivalent to the US Federal Sentencing Guidelines for Organizations (1991), which allow sentence mitigation for corporations accused of illegal actions, provided they are able to show that an 'effective compliance program' (normally involving a 'code of ethics') was in place prior to the offence. However, UK regulators are increasingly looking for evidence of monitoring systems and controls, which demonstrate that corporate businesses are being run in a compliant manner. To this end template analysis of the type described has potentially a role to play. The process of undertaking the template analysis exercise helps institutions to identify their strengths and weakness in compliance-competence and is of value in itself. It creates a framework of hierarchical analysis of the most important key issues and provides the basis for future discussion and development of these issues in a structured and straightforward format. The template can be reviewed and updated as part of an institution's corporate plan and has the advantage of being used to demonstrate to external regulators and stakeholders that such a review has been undertaken as part of an ongoing monitoring process.

\section{Research findings}

The following consists of the key findings from the case study, based upon extracts from Skandia's own ethical guidelines and quotations from the interviews with senior personnel. These interviews are illustrative of the ethical approach adopted by Skandia and to a greater or lesser extent speak for themselves.

It should be noted and recognised that Skandia has a set of ethical guidelines (2000) which state that that 'all activities of the group shall be typified and permeated by a high level of ethics' and that 'all employees must at all times take responsibility for 
ensuring that their own actions comply with the high ethical standards required' (template, 3.1). The desire to develop the appropriate ethical approach to business, as part of being a compliance-competent institution, manifests itself in a desire to do the right thing for both the customer and the institution itself:

My philosophy and what I have tried to get across, to the institution as a whole, is that we should be thinking more in terms of what we believe are acceptable practices. I can think of many examples lately where someone will say "What about this compliance problem?" I would say to them, forget compliance for a moment and ask what you think is right or wrong, particularly in the approach to the investor? It does actually focus the mind a lot (Legal and Compliance Director and Company Secretary).

This comment indicates a practical approach to compliance-competence. Rather than just apply the letter of the law, the leadership from senior management suggests a desire to apply the spirit of the law (template, 3.2.3). A spirit rather than a letter of the law approach is also highlighted in the Jackman model (2001a) as an indication that the institution is developing the correct ethical approach to its business and is in keeping with a mature institution, which has a good relationship with its regulator (FSA). The following comment raises the issue of how ethics need to be translated into daily behaviour (template, 3.2.2.2):

I think what employees need is actual behaviours. Exactly how Skandia corporate values translate into in terms of behaviours is currently left very much too individual interpretation. We have people brainstorming it. I think it is for the company to say 'these are the behaviours that we want to stand by'. To me they are not just key words. (Human Resource Manager).

However there is a real recognition that an ethical approach is an organic process that needs to be flexible and ongoing. Such an ethical approach needs to involve the staff and recognises ethics as being part of a wider external relationship (Wood, 2002, and template, 3.1.2): 
Ethics is a living and breathing culture because it's not like mathematics where you have principles and rules that are not going to change. Ethics will change over time, because what was seen as ethical in Victorian times is not necessarily seen as ethical now, society has changed. The core principles of honesty, trust and fairness are not going to change. But obviously if you are to put those down as a prescriptive list you will need a bit more meat on the bones and it's that meat on the bones that is going to change. So in terms of laying it down in a framework, I think it should be one that is able to adapt and mould itself to suit the current social and wider economic conditions (Senior Technical Trainer \& Manager of Product and Technical Team).

The adoption of institutional values and behaviours needs senior management leadership as well as institutional artefacts, such as an ethics committee and a well established 'whistle blowing procedure'. Staff and external stakeholders need to see such leadership and institutional structure if they are to accept that an ethical approach is key to the institution's development (template, 3.2.2.1) and is part of a wider compliance-competence culture. Such ethical development needs to be communicated (template, 3.2.1.3), localised (template, 3.2.1.1) and supported by a reward system (3.2.1.4) linked to staff appraisal (template, 3.3.3).

From a wider ethical compliance perspective the template analysis also shows the progress Skandia has made in responding to the FSA's requirement that institutions carry out appropriate risk assessments of their business, which are supported by internal systems and controls. This is highlighted by the approach taken with new product developments by product development teams that describe a well-formalised system of control:

We are very much risk focused and managing those risks is the way we handle projects and the way project teams are configured. So Compliance is seen as a very key team to work with. In terms of specifications we go through a high level specification of detail. They all go through a sign-off session, the walkthrough session (safety net to ensure everything is right from cradle to grave, have we missed anything, is this going to work?) right across the business in terms of the key players, including compliance. We then look at it from a system perspective and get into business requirement documents, which is a 
high level document, looking at IT systems, procedures, literature requirement, training requirements and so. Then we draft user requirement documents that flesh all of that out into detail, followed by all the IT specific documents. So there is a huge amount of documentation that goes on, that really details everything that needs to be done (Product Development Manager).

The product development team therefore acknowledges an awareness of the risks involved in new product development. This is in keeping with the Jackman model (2001a), which highlights the need for institutions to develop an appropriate ethical culture and be 'risk focussed and self policing' (template 3.1.4). They are also aware that compliance is not simply a matter dealt with by the Compliance function but is very much integrated into the product development process.

The approach is still evolving. We use risk registers (logs) to control project risk mainly focussing on financial and implementation risk as opposed to compliance risk. However for the more recent projects we have set up essentially a compliance risk register, which homes in on FSA rules. From my point of view and in terms of the role, it is not a one-man-band managing the entire spectrum. It is making sure we have properly identified and recognised all the different risks and issues in the particular development and then attaching ownership of those risks and issues to individuals. So compliance and the whole rule-book is very much spread across Skandia as a business, rather than being one hundred percent owned within the compliance function, as that is an impossible situation from their point of view (Product Development Manager).

Therefore the product development team experience indicates a developed internal compliance system of controls and a willingness to accept responsibility and to make compliance work in a practical way. The template includes references to other ethical and compliance matters arising from the interviews, such as whistle-blowing procedures (template, 3.2.4) and the recognition of ethical sub-climates (template, 3.1.5). Skandia needs to develop an internal system for whistle-blowing from one of escalation to line managers to a more formalised and internal independent process. Skandia has also recognised that within the institution some departments may adopt a 
different ethical approach. This is an interesting point as the literature suggests that within any institution there might be 'ethical sub-climates' based upon each department's job tasks and their nexus with external influences (Thompson (1967) and Weber (1995)). ${ }^{\text {vii }} \quad$ The effect of ethical sub-climates may be minimised provided there are clear ethical guidelines, which are translated into everyday behaviours (template, 3.2.2.2), properly communicated (template, 3.2.1.3) and led by the senior management. (template, 3.2.3.1).

The interviewee comments and their subsequent analysis have therefore assisted in the development of a template of analysis appropriate for Skandia. The resultant template of analysis has enabled Skandia's level of compliance-competence to be evaluated and measured so that the following key compliance and ethical findings, and recommendations can be made. While its roots are clearly based in the Jackman model it demonstrates how such a model can be operationalised to analyse an institution’s compliance-competence in a more detailed and hierarchical manner.

The following conclusions are based upon the entire case study research and the full template analyses but are not fully recounted here for reasons of brevity. ${ }^{\text {viii }}$ While this template is specific to Skandia its application has the potential to be more widely used. The template provides a tool for analysing and measuring an institution's compliance-competence that can, subject to further development/amendment, not only be utilised for other financial services institutions but also has the capability of being adopted and used in the wider domain of corporate governance. It can be used to demonstrate to external regulators and stakeholders that an analysis and evaluation of compliance-competence has been carried out, which highlights its current strengths 
and weaknesses, which in turn provides a basis for future development and improvement.

\section{Key compliance and ethical conclusions}

Skandia demonstrates a desire to go beyond the regulatory rule approach and there is evidence of responsibility for compliance matters being taken on by non-compliance staff. Skandia also shows signs of being proactive in ethical issues and seeks to adopt an open approach with the regulator. Therefore it displays the traits of a compliancecompetent institution that matches the level three-four benchmark criteria of the Jackman model and the wider research findings, arising from template analysis, indicate that it:

- is proactive and preventive in its regulatory approach, evidenced by its risk management systems, compliance and willingness to develop new processes

- has a strong learning culture and adopts a spirit not a letter of the law approach and is self-policing

- demonstrates a wide compliance responsible/ownership approach, evidenced by its product development procedures

- favours less prescription and bureaucracy and a more flexible regulatory approach based upon mutual trust and understanding, coupled with greater responsibility to act in the right way

- is aware of the issues pertaining to ethical sub-climates

- has sought to develop a corporate set of values supported by senior management and is aware of the ethical debate and the need to involve a broad range of ethical partners

- has a positive and open relationship with the regulator and understands and accepts the value of developing compliance-competence in partnership with the regulator

- is aware of the ethical debate and has already sought to establish a corporate set of values supported by senior management. It nevertheless can improve its position by more fully articulating its ethical policy and establishing the right ethical artefacts, such as an ethics committee responsible for driving forward the ethical agenda. 
The full template analysis indicates that Skandia, like most other institutions, has room for improvement. The analysis shows that to date its approach to ethics has been somewhat reactive and would benefit from stronger senior management leadership. While a great deal has been done in respect of corporate values more needs to be done in translating these into clear everyday behaviours for all staff. A more formalised approach to ethics is needed through both incorporation within the committee structure and its staff development. Therefore it is suggested that Skandia considers:

- moving away from a rather ad-hoc ethical approach towards a more clearly articulated ethical policy which has the full support of senior management, with an 'ethics champion' and involvement of all staff

- institutionalising ethics formally and explicitly into everyday working life by translating an agreed set of ethical values into ethical behaviour

- establishing the right ethical artefacts such as an ethics committee, an ethics forum and a whistle-blowing procedure

- integrating ethics into staff induction, training, performance appraisal and reward structure, and finally

- how to develop ethics as a product differentiator in consultation with the FSA.

If such an ethical approach is adopted the institution will need to identify an ethical champion at senior management level and develop an ethical policy that is supplemented by ethical codes of conduct. Such codes would need to be developed at all levels of the business so as to have real meaning for all employees. Such an ethical approach must be 'lived' by those within the institution and manifest itself in recruitment, staff development and the reward structure. An institution might also consider establishing an ethics committee as part of its corporate governance structure with direct reporting to the Board. This approach will strengthen an institution's 
corporate governance framework and contribute to greater transparency and articulation of the division of responsibilities in line with the OECD principles of corporate governance (April 2004). It should encourage a more proactive treatment of stakeholders and help with the effective monitoring of management by the Board, and the Board's accountability to the institution and the shareholder.

\section{Summary}

While the template of analysis developed is most pertinent to Skandia, a UK life assurance company, the generic assessment criteria are of relevance and value to all financial services institutions and the wider business environment. The tool of template analysis builds upon the Jackman model of developing the right values and culture. It allows more detail and meaning to be added and has highlighted the significance and value of an ethical approach for institutions, which can be monitored by external stakeholders/regulators. The importance of monitoring an institution's corporate governance performance has been stressed by Mallin et al. (2005). The ethical and cultural dimension is part of compliance-competence and is rooted in the literature associated with the financial services sector. Template analysis has the potential of assisting institutions in their understanding and formulation of a strategy on compliance-competence and underlying ethical issues. The template, therefore, is a potential tool of analysis for any institution wishing to evaluate its own compliance competence and ethical development as part of wider corporate governance debate. While recognising the template developed is only a starting point for institutions wishing to develop their own individual template it, nevertheless, provides a practical framework of analysis (Laughlin, 2004) and is of assistance to external stakeholders when subjectively evaluating an institution's compliance-competence and ethical 
approach. Finally, the ability to evaluate an institution's compliance-competence benefits the regulators and those it regulates, and informs those responsible for sound corporate governance.

\footnotetext{
${ }^{\mathrm{i}}$ The Financial Services Authority (FSA) created by the Financial services and Markets Act 2000 replaced the Securities and Investment Board (SIB) established by the Financial Services Act 1986.

ii Jackman, D. former head of Industry Training and Business Ethics Adviser to the Financial Services Authority .

${ }^{\text {iii }}$ Note: this is not an evaluation of how compliant a financial institution is with specific existing regulations.
}

iv The questionnaire was amended in light of the responses received by previous interviewees in order to confirm the essential elements of compliance-competence and to develop a template of analysis. The questions were structured in a way to gain an understanding of Skandia's understanding of and approach to regulation, the regulator, ethics, systems and controls, and training and HRM issues

${ }^{\mathrm{v}}$ For the interested reader on template analysis King provides a list of relevant literature and examples of research using template analysis, [online] available from: http://www.hud.ac.uk/hhs/research/template_analysis/literature.htm. [Accessed 25 March 2006].

vi The four themes arising from the template analysis are: regulatory, compliance, ethical and partnership. A copy of the full template of analysis is available from the authors upon request.

vii Thompson identifies the three types of departments as 'technical, buffer and boundary-spanning'. Accordingly to Weber (1995, p.511) the 'technical core departments are the institutions basic production activity' being the most protected from external influences and surrounded by the buffer departments which tend to be 'specialists, adept at performing their customized task in service to the whole organization’ and its various internal stakeholders.

viii Ibid: endnote vi.

\section{References}

Arjoon, S. (2005) Corporate governance: An ethical perspective. Journal of Business Ethic, 61(4) 343352)

Baker, E.L. (1980) Managing organizational culture, Management review, 69 (7) 8-13.

Combined Code (2003) The combined code on corporate governance. London: The Financial Reporting Council.

Creswell, J.W. (2003) Research design: qualitative, quantitative, and mixed methods approaches. $2^{\text {nd }}$ ed. CA: Sage.

Edwards, J. (2003a) Compliance competent life assurance companies: a partnership approach. Journal of Financial Regulation and Compliance, 11 (1), 10-20.

Edwards, J. (2003b) Individual and corporate compliance competence: an ethical approach. Journal of Financial Regulation and Compliance, 11 (3), 225-235.

Edwards, J. and .Wolfe, S. (2004) The compliance function in banks. Journal of Financial Regulation and Compliance, 12 (3) 216-224. 
Edwards, J. and Wolfe, S. (2005) Compliance a review. Journal of Financial Regulation and Compliance, 13 (1) 48-59.

Financial Services Authority (FSA): (2002) An ethical framework for financial services. Discussion Paper 18, (Oct.), [online]. FSA. Available from: www.fsa.gov.uk/pubs/cp/cp18.pdf [Accessed 28 November 2005]

Higgs, D. (2003) Independent review of non-executive directors. [online] DTI. Available from: http://www.dti.gov.uk/cld/non_exec_review [Accessed 28 November 2005]

Jackman, D. (2001a) Why comply? Journal of Financial Regulation and Compliance, 9 (3), 211-217.

Jackman, D. (2001b) Values-led regulation. In: C. Moon and C. Bonny eds. Business ethics. London: Profile Books, 186-193.

Jackman, D. (2004) Does regulation make it worse? Journal of Financial Regulation and Compliance, 12 (2), 106-110.

King, N. (1998) Template analysis. In: G, Symon and C. Cassell, eds. Qualitative methods and analysis in institutional research: a practical guide. London: Sage. 118-134.

Laughlin, R. (2004) Putting the record straight: a critique of methodology choices and construction of facts: some implications from the sociology of knowledge'. Critical perspective on Accounting, 15, 261-267.

Lincoln, Y.S. and Guba, E.G. (2000) Paradigmatic controversies, contradictions, and emerging confluences. In N.K. Denzin and Y.S. Lincoln Eds. Handbook of qualitative research. $2^{\text {nd }}$ ed. CA: Sage. 163-188.

Mallin, C. Mullineux, A. and Wihlborg, C. (2005) The financial sector and corporate governance: the UK case. The Financial Sector and Corporate Governance, 13 (4), 532-541.

Moon, C. and Bonny, C.. (2001) Attitudes and approaches. In C. Moon and C. Bonny eds. Business ethics. London: Profile Books, 22-37.

Newman. W.L. (2000) Social research methods: qualitative and quantitative approaches. $4^{\text {th }}$ ed. Boston: Allyn and Bacon.

Newton, A. (1998) Compliance: making ethics work in financial services. London: Financial Times Management

OECD April 1999, http://www.encycogov.com/WhatIsGorpGov.asp)

OECD April 2004 The OECD Principles of corporate governance. Policy Brief, August 2004.

Otley D. and Berry, A. (1994) A case study research in management accounting and control. .Managemnt Accounting Research, 5 91), 45-65.

Paine, L.S. (1994) Managing for organizational integrity. Harvard Business Review, 72 (2), 106-117.

Parker, C. (2002) The open corporation: effective self-regulation and democracy. Cambridge: Cambridge University Press.

Scapens, R. W. (1990) Researching management accounting practice: the role of case study methods. Brutish Acconting Review, 22 (3) 259-81.

Schwandt, T.A. (2000) Three epistemological stances for qualitative inquiry. In: N.K. Denzin and Y.S. Lincoln eds. Handbook of qualitative research. $2^{\text {nd }}$ ed. CA: Sage. 189-213. 
Skandia (2000), Ethical guidelines for the Skandia group and its employees. Skandia Life Assurance Company Ltd.

Skills Council for Financial Services: (2003), Jamison, C. and R. Steare, eds. Integrity in practice: An introduction for Financial Services, (Sept.).

Tiner, J. (2005) The future of financial regulation in Europe. Speech to the French Chamber of Commerce, 25 (Nov.) [Online] Available from: www.fsa.gov.uk/pages/library/communications/Speeches/2005/1125_cm.shtml. (Accessed 22 February 2006).

Thompson, J. D. (1967) Institutions in action. New York: McGraw-Hill.

Weber, J. (1995) Influences upon organizational ethical subclimates: a multi-departmental analysis of a single firm. Institutional Science, 6 (5), 509-523.

Wood, G. (2002) A partnership model of corporate ethics. Journal of Business Ethics, 40 (1), 61-73.

Yin, R. K. (2003) Case study research: design and methods. $3^{\text {rd }}$ ed. London: Sage. 